this institution, where it is found to give highly satisfactory results. Photographs of $\eta$ Orionis which have been made with it exhibit the elongation of the star, although the distance between its components is only about $1^{\prime \prime}$. The newspaper report to which Sir Howard Grubb refers, that a patent was granted for the invention, is without foundation. The Messrs. Clark have never patented any of the improvements made by them in optics, and have had no intention of deviating from their usual practice in this instance.

Edward C. PiCKERING.

Harvard College Observatory, Cambridge, U.S., March 26.

\section{Life of Fleeming Jenkin.}

I HAVE read with singular pain a paragraph in your notice (signed with the initials of one whom I admire and respect) of my Life of Fleeming Jenkin. To accuse a man of falsehood in private life is a strong step. But I must explain to your reviewer, I might lie to him all day long and not be so disgraced as if I put one single falsehood in a book. For the making of books is my trade by which I live; I supply them on honour, and the public gives me bread for them in confidence. Your reviewer will perhaps more readily understand what he has done (I am sure in ignorance) if I supply him with a parallel. To say that a man of science was a liar would be highly disagreeable; but if I were to say he had falsified an experiment, and to say so publicly in print, I should be curious to see the expression of his face.

I dwell upon this because it is plain your reviewer scarcely understands what iiterature is, and I fear others may be equally at sea. On the merely personal matter, that I am supposed to tell a deliberate falsehood on my own authority and about my dead friend, I will make but one remark. Hasty reading is the fit precursor of hasty writing; in no word have I indicated that the certificate in question was "worthy the name"; and the terms of the document are at the reviewer's service to-morrow, if he be curious. March 28.

$$
\text { ROBERT LOUIS STEVENSON. }
$$

\section{THE HITTITES, WITH SPECIAL REFERENCE} TO VERY RECENT DISCOVERIES

III.

THE conclusion has been already expressed that the Hittite inscription of the Tarkutimme seal is, in the main, ideographic, and that the phonetic element is supplementary; that, in fact, regarding the figure of the king as part of the inscription, the sense is fully given without taking into account the phonetic element. Some scholars and investigators have, however, taken a different view. This fact, together with the alleged resemblance of some of the Hittite hieroglyphs to characters of the Cypriote syllabary, has had much influence on certain recent attempts at deciphering the Hittite inscriptions. With regard to the alleged analogy of the Hittite and Cypriote characters, it may be allowed that the derivation of the latter from the former is in itself by no means impossible. As yet, however, the evidence of such derivation which has been presented is certainly inadequate : to a great extent it is little better than visionary. Moreover, if, from closeness of resemblance or otherwise, satisfactory proof of the derivation had been given, it would by no means necessarily follow that, when all or any of the Hittite inscriptions which we possess were sculptured, the Hittite writing had become already so far developed that the hieroglyphs generally, or in great proportion, had acquired distinct syllabic values. As to how far resemblances between the Hittite and Cypriote characters give evidence of essential connection or derivation, the reader may perhaps satisfy himself by inspecting the list given by Dr. Isaac Taylor ("The Alphabet," I 883) and reproduced by Prof. Sayce in Wright's "Empire of the Hittites," I 886, chap. xi. More extended lists have been

x Based on Lectures delivered by Mr. Thomas Tyler at the British Museum in January 1888 . Continued from p. 540. given by Captain Conder (who follows to a considerable extent in the track of Prof. Sayce) in the plates of his "Altaic Hieroglyphs." But, as it seems to me, in neither case have the Hittite characters been always given with such essential accuracy as is desirable. This remark applies more especially to some of Captain Conder's figures, notwithstanding his observation in "Altaic Hieroglyphs," p. 35 : "A careless reading and confusion of distinct emblems must lead us wrong; and for this reason exact copies are indispensable." But, even if this objection be waived, the evidence must still be regarded as inadequate. As to "the subject of the inscriptions," Captain Conder remarks that it "is exactly what we should have expected. They occur on statues of the gods, and they are invocations only" (op. cit. p. 149). Now that the inscriptions "occur on statues of the gods" is certainly not true with regard to most of those which are known to us, and as we have them. The "doorway inscription" in the British Museum and the inscriptions from Hamath are connected with no statue whatever. In other cases, where there is a statue, or large figure in relief, it is by no means to be assumed that the figure is always that of a deity. But, as a specimen of what Captain Conder finds in the Hittite inscriptions, I may give his "free rendering" of the first two lines of that very ancient inscription in the British Museum of which I have just spoken as the "doorway inscription." I give Captain Conder's "free rendering" rather than his "verbatim translation," as likely to convey a less unfavourable impression:-

"I. Prayers of the Monument of Set. Powerful words for the living fire, the Most High .... the divine. . . .

" 2 . . . . to . . . (pour?) Tammuz, Âa, living fire, Most High descending (propitious?) Thee strong Set ..." ("Altaic Hieroglyphs," p. 194).

With respect to utterances of this kind it is not necessary to say much more than that they certainly have not the claim to consideration which would result from a connected and congrous rendering. Such a rendering might have been adduced as giving some answer to the position that evidence is wanting as to the Hittite hieroglyphs representing, in the main, syllables either in the Accadian or Altaic language, or in any other language whatever. Then, as to the inscriptions being concerned mainly or exclusively with theological prayers and invocations, the analogy of the Assyrian inscriptions-which the Tarkutimme seal with its cuneiform legend itself suggestswould rather lead us to expect that the subject-matter of the inscriptions is usually success in war, with allusions to the gods, and prayers and thanksgivings, chiefly in relation to such success. And this more realistic view is in accordance with the heads of oxen and of asses, with the clubs and the swords, and other symbols of equally materialistic character which appear on the inscriptions. Moreover, somewhat more than a year ago, the British Museum fortunately obtained an engraved stone of unquestionable antiquity, giving evidence in accordance with that of the seal of Tarkutimme, and tending to show that the Hittite inscriptions are in the main ideographic or pictorial.

The allusion just made has reference to a circular hæmatite seal from Yuzgât, in Asia Minor, which was added to the antiquarian treasures of the Museum in October 1886. Yuzgât is not very far from both BoghazKeui and Eyuk; therefore the discovery in this locality of an important Hittite antiquity can scarcely excite surprise. For the present, the seal is named, most conveniently, from the place where it was found, "the Yuzgât seal." This seal resembles the seal of Tarkutimme in being circular; and the two seals agree also with reference to there being an inner circle which divides the figures or characters round the circumference from those in the central space. The seals differ, however, in size, the Yuzgât seal being much the smaller. The latter seal, moreover, is not bilin- 
gual, and it has not a convexity of surface, like the seal of Tarkutimme. The Yuzgât seal, in fact, is flat, with the exception of the central space, which is concave, and which consequently causes a central convexity in the impression. On careful observation it may be perceived that the figures on the circumference divide themselves into three groups. In the centre of the first group is the winged solar disk supported on a cone. It seems not unlikely that this cone is essentially identical with the "king"-symbol already discussed in connection with the Tarkutimme seal. Here it may point to the prominence and pre-eminence of the sun-god as ruler of the world, all things animate and inanimate being subjected to his sway. The solar king in the centre, with the two figures, one half-kneeling and one standing, on each side, constitute the first group. These two figures on each side present features of very great interest. Nearest to the solar emblem are two horned ox-headed figures, apparently masculine, with the palms of the hands uplifted, in the act of adoration. The ox's head is not here presented in profile, as is usually the case on the Hittite monuments, but the horns and ears and the tapering muzzle are depicted with sufficient clearness. These figures may be taken as representing the moon-god, and recalling in

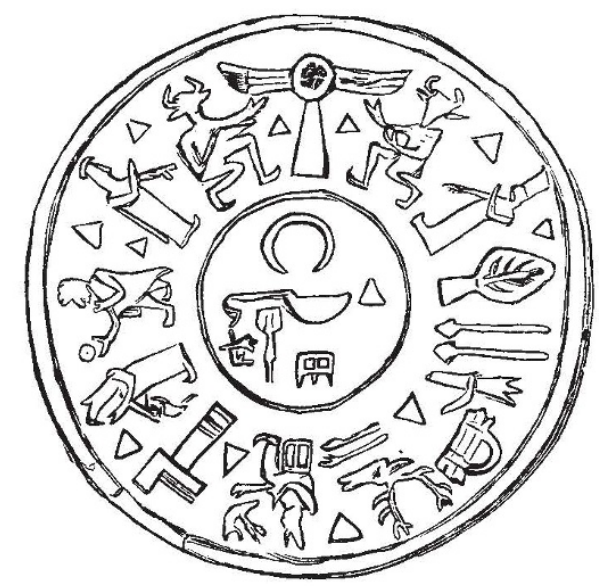

FIG. G.-The Yuzgât seal in the British Museum (enlarged).

their masculinity the Babylonian moon-god Sin. This seeming masculinity should be remembered if a comparison is made with other ox- or cow-headed figures of deities, as, for example, those found by Dr. Schliemann, and about which there was not very long ago some discussion. More distant from the solar emblem are two draped figures which we may regard as types of the female deity Ashtoreth, viewed as a moon-goddess. There is tolerably clear evidence that one of these draped figures is horned, and probably also ox-headed. In the case of the other, on account of a flaw in the seal, this is not equally manifest. Though the attitude is different, these female lunar deities appear also to be worshipping the sun-god. The lunar deities, like other figures on the seal, appear all to have turned-up toes, indicating probably the so-called "Hittite boots." 1 With these figures of lunar deities may be compared a symbol of Ashtoreth as a moongoddess on the longest Hamath inscription, giving a

I It is worthy of note here that about a third of the circumference is occupied by these sacred figures. From this fact may be derived a probable explanation of the vacant space over the king's head in the seal of Tarkutimme (supra, p. 537). The engraver, we may supp sse, when he commenced engraving the king's name, intended to devote a third of the circumference to sacred objects, or at least to leave it vacant as usually so devoted. He, however, miscalculated the space at his disposal. Resolved, however, to leave some vacant space at the top, and especially over the king's head, he was compelled to leave a space in the middle of a word. Pruf, Sayce has given a different explanation (Zeitschr. fïr Assyriologie, November r886.) crescent moon with the head of an ox above and within it, while beneath is an equilateral triangle or else a cone. ${ }^{1}$

If we strike a diameter across the seal from the solar disk, it will come, towards its extremity, to what is apparently a king seated on his throne and wearing a cap with a horn in front. Between the king and the group of sacred figures already described, there is on each side a distinct group, making up altogether the three groups which I have mentioned. Of the two groups not yet described the more interesting, on account of its resemblance to what may be seen on the inscriptions, is the group behind the king. There appears strong reason to believe that in this group we have a genuine example of picture-writing, in which the successful chase of a stag is represented. There is first (most remote from the king) a tree, indicating the forest, where the hunt occurred. Then come two javelins, used no doubt by the hunters of the stag, and next after these there is a sort of trident, employed, I should suppose, to give the coup de grâce, and of this trident I shall have an additional word to say directly. Next to the trident we find a bundle, or basket with a handle, which naturally suggests the idea of carrying. Then there is a stag's head with large antlers, and beneath it two arms with hands pointing towards the king. As the king is sitting with his face towards the group of figures in front of him, the engraver, in order to denote the king's acceptance of the stag's head (which may represent the whole

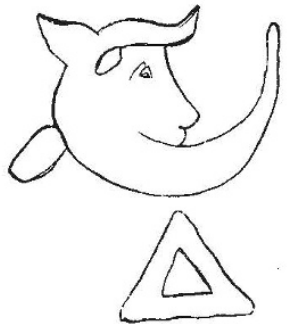

FIG. H. -Symbol of Ashtoreth, on Hamath inscription.

stag), has given on the other side, and above the king's arm outstretched to receive it, the stag's head a second time, of smaller size and consequently somewhat less artistically rendered. In the third group, beginning with the figure most distant from the king, we have what is very likely a tributary king, bringing a gift or tribute. Before him is what I take to be a woman veiled after the Oriental fashion, and with probably a baby suspended from her arm. With this appendage she may possibly have been regarded as likely to prove more acceptable to the king. Between the woman and the king is what I have regarded as a conventional symbol of a castle, indicating that the presents were received by the king in his castle. The symbol is difficult to determine; but I cannot find any more probable explanation. What it is particularly important to observe is, that the other two groups on the circumference of the seal being pictorial or irleographic, it is scarcely possible to escape the conclusion that the third group-that which I have regarded as representing the successful chase of a stag--is of the like character.

Of the objects in the central space I am unable to speak with any confidence. They may be so placed as objects of interest merely, or, taken phonetically, they may denote a name. There is a crescent, beneath it a nearly semicircular knife with a handle (if it is not possibly a ladle seen in profile), a mace or club, a sort of grating, and a trident smaller than that in the outer

' Mr. Rylands's drawing of the inscription gives the former, and this may possibly be right, though the cast of the inscription in the British Museum does not make this altogether clear. The original is unfortunately at Constantinople. 
circle. Besides these objects, there is an equilateral triangle, like eleven others among the symbols in the outer circle. I was inclined to think that these triangles might perhaps in some way modify the meaning of the other symbols, till I noticed that not only does their size differ, but also that the vertex of the triangle, usually directed upwards, may be directed downwards to suit better the shape of the surrounding ared. This is clearly seen in the space between the larger stag's head and the king. We cannot, however, come to the conclusion that these triangles are employed merely for artistic effect, and to fill up vacant spaces, even if these objects were not wholly disregarded. The recently-discovered Tarsus seal gives important evidence in favour of the sacredness of the equilateral triangle. We must conclude that the triangle is employed on the Yuzgât seal as a sacred symbol, and that as such its vertex is usually directed upward, but that this position is sometimes varied in accordance with the exigencies of space.

With regard to the group on the seal, concerned with the chase of a stag, I have spoken of its resemblance to what may be seen on the Hittite inscriptions. This is especially noteworthy with regard to the group represented in Fig. I, from the so-called doorway inscription in the British Museum. Progress in decipherment is not as yet sufficiently advanced to enable us to determine the precise significance of all the symbols, but of the general meaning there seems no room to doubt. Beginning from the end of the figure to the reader's right, the meaning

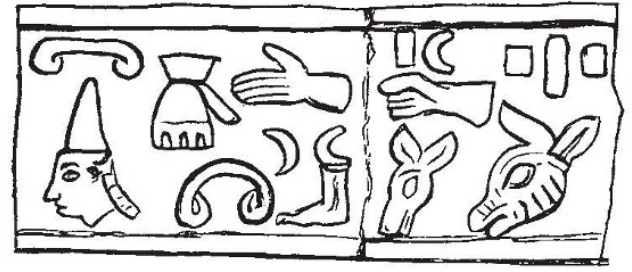

Fig. I.-Group of symbols from Jerablûs monument in the British Museum.

intended to be conveyed appears to be that booty in the shape of many oxen, asses, and other treasure, which had been obtained by the powerful assistance of the gods, was presented to the king. The parallelogram with a square on each side I regard as indicating "many." That this was the sign of plurality was the opinion of my distinguished friend, the late Dr. Birch. The head of the ox and of the ass do not seem to require remark; but above the latter is a massive and powerful right hand, with fingers clenched, and with part of the fore-arm. This would be a very appropriate symbol of strength or power. ${ }^{1}$ Close above the right hand, and at the top, are a straight stroke, or parallelogram, with a crescent beside it. These symbols combine to form the usual symbol of deity on the Jerablûs monuments. I can only assert this now ; but the evidence is abundant, and I hope to prove it fully in the sequel. Next after the closed fist with the symbol of deity comes part of an arm with the hand open and pointing towards the king. The analogy between this hand and those beneath the stag's head on the Yuzgât seal is almost too obvious to require remark. Of the value of the two crescents, which are, so to speak, back to backa symbol not uncommon on other inscriptions-I cannot speak with any confidence. ${ }^{2}$ At the bottom is a foot, which would very appropriately denote the act of going to the king. Next to the open hand at top is a symbol

I Cf. "The saving strength of his right hand" (Psalm xx. 6), and "his right hand, and his holy arm, hath gotten him the victory " (Psalm xcviii. I). But the figurative use of the right hand as a symbol of strength presents no difficulty.

${ }^{2}$ It seems not unlikely, however, having regard to the symbols which the two crescents accompany here and elsewhere, that they distinguish a particular kind or class of persons. the origin of which Mr. Rylands, to the best of my recollection, formerly referred to a bag grasped and pressed together a little below its mouth, by a hand. If this view is correct, this symbol has become, like many others, somewhat conventionalized. The bag is depicted so as to enable us to see within it at the bottom. Here are three objects, probably pieces of gold or silver used as uncoined money; and the number three may, as elsewhere, denote a great many. Beneath the bag is what has been regarded as a yoke; and, having regard to the bundle or basket on the Yuzgât seal, this may very well denote the carrying to the king. Last comes the head of the king himself, with conical cap and "pig-tail," and above him.is a symbol which is perhaps best regarded as derived from the idea of a canopy above the king. As on the Yuzgât seal, the king's face is turned away, but this is because the inscription is intended to be read with the faces-that is, in the direction towards which the faces point - and not, as some have asserted, against the faces. The former arrangement is the more natural, and would have a priori the greater probability, but the latter is commonly, though, as Dr. Birch once said with reference to this point, not invariably, observed on the Egyptian monuments. In support of the latter view it is alleged that there is usually, at one end of the first line of the inscriptions, part of a figure with the face turned away from the other characters in the line, but with the fingers pointing towards the face or mouth, as though indicating "I have something to say." This figure, it is

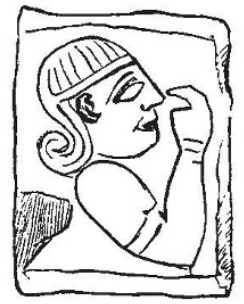

Fig. K.-Figure from Jerablûs monument in the British Museum.

urged, must mark the beginning of the inscription, and, as the face is turned away, the characters must be read against the faces. But, in the first place, the figure referred to occurs elsewhere, and not solely and invariably at one end (to the reader's right) of the first line. The significance of the figure is, in all probability, as stated, but, as the figure is evidently that of a servant or minister, and not that of the king or other great personage with whose doings the inscription may be supposed to be concerned, we should expect in the first place, and before the particular message, or the subject-matter of the inscription, is entered upon, a statement of the name and titles of the person from whom the message proceeds. At the commencement of the Assyrian inscriptions there is often a very copious statement of this kind. And in fact on three of the Hamath inscriptions there is what appears to be a name immediately before the figure with the hand towards the mouth. The group of symbols discussed just above gives pretty strong evidence as to the direction in which the inscription in which they occur is to be read; and I hope to give some further evidence on this point in the sequel.

A word must be here added with respect to the trident on the Yuzgât seal. The trident is more usually associated with the sea and the sea-god than with warfare on land, or the chase. It was employed, indeed, in the Roman arena ; but, as the gladiator using it was furnished also with a net, there may seem to be still some reminiscence of the sea. With regard to the trident being employed in the chase, I may adduce the evidence of a curious seal-impression which I obtained some time ago from Mr. Ready, of the British Museum. The objects 
depicted are apparently the head of an animal, probably some kind of goat or ibex, parts of the animal's carcass, and a trident essentially similar to those on the Yuzgât seal. Mr. Ready is unable to tell me in what

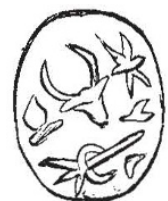

FIG. L-Seal with figures (enlarged).

collection this curious seal, which is very small, is to be found. So far as I am aware, it is not in the British Museum.

\section{PRACTICAL EDUCATION.}

PLAINLY speaking, it must be admitted that to an impartial observer the great problem of anthropology is this: Is the mind, or soul, a mysterious and supernatural, yet at the same time a definite limited quantity, with certain set "spiritual" functions, or is it, being of material growth, capable of infinite development? The former is the metaphysical view of the subject, the latter that of the evolutionary physiologist. Without deciding which is the true school, it may be remarked that the metaphysicians have long ceased to teach anything new, while physiology gives us, almost daily, facts of an astonishing nature. Here and there in the works of Darwin, Carpenter, Haeckel, Huxley, Bain, Maudsley, Spencer, and David Kay, we find what would have been "conclusions most forbidden," even to a Rosicrucian or Cabalist, in days of yore. And these are that man may develop his memory and other faculties in the simplest and most practical manner, as a bee builds its combs, grain by grain, until he shall far surpass what he has ever been. These discoveries as to man are in exact step with the stupendous revelations of the spectrum analysis, and the scientific reduction of the elements.

I recently published a work, the result of many years' labour, entitled "Practical Education," in which I endeavoured to give the results of experiments with nearly two thousand pupils, combined with the suggestions in the works of the writers above alluded to ${ }^{1}$ Having Iong been occupied with investigating the problem of technical education, I offered to the School Board of Philadelphia, in 1880 , to devote myself entirely to the experiment of ascertaining exactly what children could do. That boys and girls from eight to fourteen years of age could not set type, make shoes, execute heavy carpenters' work, \&c., had already been ascertained in Pennsylvania at a cost of about $£ 200,000$. I had, however, learned in Egypt, South Germany, and other places, that the very young can execute the decorative work which is known as that of the minor arts, and that so well that it had market value.

Walter Smith, now of Bradford, had published a system by which design was taught at the same time with drawing. I had, two years before I met with Smith's system, which is now much employed in America, set forth the same idea in a work entitled "The Minor Arts." It soon became apparent that, by beginning with design, the youngest child developed-with invention-interest, attention, and intelligence. The results went far beyond my anticipation. It was found by the most careful inquiry that the pupils who attended the art classes had the highest "averages" in other studies, such as arithmetic, She "Practical Education" (London: Whittaker and Co., Paternoster
Square). geography, and composition. This fact is the more striking from this - that the School Board, having made inquiries unknown to me, found that among i io,000 pupils the 200 who attended the Industrial Art School were among the first in everything.

An immediate inference from this fact is that visual perception or eye-memory (as set forth by Francis Galton) and attention or interest (as explained by Dr. Maudsley) are also factors which enter into the training of the constructive faculty. These, as is clearly explained and very fully illustrated by David Kay in his admirable work on "Memory," lead us to the conclusion that memory, by a simple process of accretion and repetition, may be developed to an incredible extent even in children. Practically, this was nothing new. Before the invention of printing, men by millions, among Druids and Brahmins and Northmen, Red Indians and mediæval scholars, Chinese and Japanese, had shown that an individual could remember perfectly what is now represented by a library. Max Müller has proved this. I myself have known a graduate of Pekin who fully illustrated it.

Memory is not "mind" or intelligence. Yet the works of Homer, the "Mahabharata," and the great scientific grammar of Pänini, were taken down and preserved for centuries by memory alone. The great history of Japan, by Hirata Atsune, was composed without the author's taking a note, and written from recollection, without reference to an original work. What man has done man may do. The deduction from all this is as follows :-

Firstly, that memory may be trained in mere children, by an easy process of committing by heart and constant reviewing, to such an extent that, guided by attention or determination, anything once read or seen may be accurately recalled. A great collection of illustrations of this may be found in Kay's "Memory," and in my own work on "Practical Education."

Secondly, that to counterbalance mere memory the mind must be trained by exercises in quickness of perception. These, in the beginning, may be merely mechanical. There are steps from inducing an infant to notice an orange on the floor up to simple games, from games to mental arithmetic or mental geography and grammar, to problems requiring the highest intelligence. The process is like that in developing memory-little by little with constant reviewing. And, as is the case with memory, all this has been established by innumerable practical examples. But with the one, as with the other, there should be no endeavour to cultivate thought or intellect or imagination until both are fairly mastered.

Thirdly, memory and quickness of perception blend and are developed in the awakening of the constructive faculty or in design, and its application to modelling, embroidery, wood-carving, and similar easy arts. And to those who object that all this does not awaken the higher faculty of intelligence or thought, it may be replied that experience or experiment have demonstrated the contrary. It is true beyond denial that a boy or girl who remembers readily and perceives quickly, and who has been trained to invention by designing, does think. Call them, if we will, only the tools of the great trade of thought, and a training to their use, is there no difference between two children of equal capacity, brought into a shop, when one knows what everything around is meant for, and how to handle it, when the other is yet to be taught? But the fact is beyond all dispute that children, even if trained to design alone, begin to think in every way. The experience of the Philadelphia school, and more or less that of every well-conducted Kindergarten, prove it. The trouble is, according to the requirements of a late review, that people ask for genius at once from an infant. "Teaching children to remember is not training them to think." But it is the foundation-stone. 